\title{
Research on Management of Educational Statistics against the Background of Information Disclosure
}

\author{
Juan Xu \\ Hunan Modern Logistics Vocational and Technical College \\ Changsha, China
}

\begin{abstract}
With the publication of information disclosure, a series of irregularities and inconsistencies have emerged in the educational statistics data published by the government departments. In view of the problems in the education statistics, the reasons for the problems are analyzed from the school level, the Ministry of Education, the directly affiliated institutions with administrative functions, and the state. The causes of the problems are from the national level and the Ministry of Education and the directly affiliated enterprises. Targeted countermeasures are proposed at the unit and school levels. For the national level and the Ministry of Education and directly affiliated institutions, it is necessary to formulate and improve the education data management system and methods, and strive to strengthen the construction of statistical information, establish a unified data center for educational data, open government affairs, data sharing, and further deepen. System reform; for grassroots schools, promote the implementation of school-level data centers, system, standardization, overall planning, unified standards, and create conditional utilization data.
\end{abstract}

Keywords-information disclosure; education statistics; management

\section{INTRODUCTION}

During the "Twelfth Five-Year Plan" period, the informationization construction developed rapidly, and the level of informatization was greatly improved. The informationization construction of colleges and universities also experienced a "leap-forward" development [1], and the functions of digital business software systems continued to expand. With the advent of the Internet of Things, mobile Internet, cloud computing, big data, and intelligent era, data and computing are everywhere. Various digital business software systems are rapidly generating large amounts of data [6]. The same is true for educational systems. A large amount of data. With the publication of information disclosure, a series of problems have appeared in the data information published by the education and government departments.

\section{PROBLEMS IN EDUCATIONAL STATISTICS UNDER THE BACKGROUND OF INFORMATION DISCLOSURE}

\section{A. The same indicator data published by different time different departments and different work items is inconsistent}

With the publication of information disclosure, the public's demand for government affairs information has increased, government information has been made public, government power has been supervised by the public, and the same indicator data published at different times, in different

\footnotetext{
1.Hunan Provincial Social Science Results Review Project (Project

Number:XSP19YBC289),

2.Hunan Provincial Bureau of Statistics Project(2018 A39)2: Management and Open Research on Education Statistics in the Context of Information Disclosure,

3.Hunan Modern Logistics Vocational and Technical College School-level Project (JYC201819)
}

departments, and different work items are inconsistent. It is mentioned by the public. These inconsistencies are mainly reflected in the inconsistency of the same indicator data at different times, the different data published by different leading departments, the inconsistency of multi-source data measurement units, the consistency of indicator names but different indicator data, and the inconsistent index names but actual connotations. A completely consistent question, etc. It is precisely because of these problems that the grassroots schools and the Ministry of Education and the directly affiliated institutions with administrative functions have derived a series of corresponding problems in the management of educational data.

\section{B. Problems in the management of grassroots schools}

1) Inconvenient for school management

Data is the basis and support for school normative management and management decision-making, because each business system software is independent of each other, and there is no unified and standardized data sharing mechanism. The same indicator data generated by different business departments is different. For example, the number of students in a school, the number of students in the academic system, and the number of students in the student management system. Sometimes the data provided by the two systems is not the actual number of students. The reason is that students have the phenomenon of adjusting their majors and transferring them. The school's business systems have not updated the student status in time, and there are no sharing mechanisms and platforms. Therefore, even if a department reports a student change, other departments The relevant information was not received, resulting in an inconsistency in the number of students in a school. Of course, there were inconsistencies in the number of students reported from different departments. This also resulted in the same number of students at the same time in the same school. Other data also exist in this phenomenon, such as teachers, service funds, etc. In addition, there is a phenomenon of data confusing, and the definition of data is not clear. The problem of different data is not easy for school management to make decisions. It also reflects the irregularity of school management.

2) Increase the burden of multiple times and multiple data collection in schools

As a grassroots education unit, the school is the cradle of training and cultivating qualified builders and reliable successors of the all-round socialist cause [1], its essence is to cultivate high-quality talents with social needs, service industry, innovation leading industry, and high-skilled research and 
development. In the process of cultivating talents, it is obliged to publish the data generated in the process of talent cultivation for the higher education departments and third parties to the society. However, with the advancement of informatization, a series of problems have emerged in the early stage of informationization. For example, various types of statistical reports have emerged, and grassroots schools have a feeling of being overwhelmed. Currently, for higher vocational colleges, platforms or systems for reporting data are required. There are talent training work status data collection platform, evaluation data platform, professional construction platform, high-base report, financial expense table, laboratory data statistical report, teacher information collection system, vocational education group platform statistical report, continuing education report, scientific research system report And so on, each system has corresponding data that needs to be reported. The key problem is the duplication of these data and the inconsistency of indicators and the inconsistency of time nodes, which greatly increase the burden on grassroots schools. The reporting department of the relevant data complains, "I have not reported the reasons why I have to repeat the report." one slice.

The reason is that the school lacks a data center, the data of the school is scattered or even confusing, and what data is temporarily needed to collect data temporarily; the second is that different departments have more or less statements because of different concerns. different.

\section{Problems in the education data management of the Ministry of Education and the directly affiliated institutions with administrative functions}

The Ministry of Education and the directly affiliated institutions with administrative functions as the education management department should master the dynamics and information of education, and the education data is the basis for reflecting the educational dynamics and information. Therefore, the standardization and unification of educational data directly affect education. The basic situation of the industry. Due to the national system and other reasons, the Ministry of Education and the directly affiliated institutions with administrative functions obtain the data resources they need from the perspective of their respective responsibilities. These data resources are effective for the same department, but due to lack of The data sharing and interconnection mechanisms and specifications of various departments, the digital data resources between different departments are inconsistent and conflicting. For example, the State Supervision Office has a set of data reports. The Secretary has a set of data reports and various administrative departments of the Ministry of Education. Class report. In addition, it is precisely because of the lack of data sharing mechanism that each department becomes a big data center that is neither a big data center nor a real sense, because no matter how large, diverse, and variable data is mastered, if the data is unreal. Then, what is the point? The value of the data is only played in this department and cannot be shared, because once it is shared, it is "heavy." The conflicts and inconsistencies between these data are widespread. This is very inconvenient for the Ministry of Education to manage and master the true dynamics of education. The quality of educational data cannot be guaranteed.

\section{Contrary to the original intention of informatization construction}

The fundamental purpose of education informatization is to promote quality education and cultivate innovative high-quality talents. The ten-year development plan of education informatization pointed out that the role of information technology in the current education development should be fully utilized. The ultimate goal is to significantly improve the level of education management informationization. The five action plans include school informationization capacity building and improvement action plan and national education management. Information system construction action plan to build a national education management information system. In reality, different time, different departments, and different projects have published inconsistent data for the same indicator; the lack of data sharing, interconnection mechanisms, data islands, data specifications and other issues are contrary to the original intention of informatization construction.

\section{ThE ANALYSIS OF THE REASONS FOR THE PROBLEM}

\section{A. On a school level.}

1) Each digital business system software is independent

During the "Twelfth Five-Year Plan" period, the informationization construction of colleges and universities developed rapidly, and the types and functions of digital business software systems continued to expand. The hardware systems of various institutions and digital business software systems are rapidly generating large amounts of data. However, 1) various business systems of vocational colleges The design is designed to meet the needs of the department, and the functions are divided. The information systems and data of some departments are independent, they cannot interact effectively and in time, and the ability to work together is lacking. The problem of information island[2] is very prominent. 2) Lack of personalization for users The ability of information service, management and service level can not be well connected, and the management of light service is difficult It is difficult for a single department to query and decide the information of the entire school on its own information set. The benefits of each business system are not fully Use and mining.[3] 3) For the education administration department, many platforms, such as the evaluation platform of the State Supervision Office, the professional construction development platform, and the innovation development action plan platform, have invisibly increased the workload for vocational colleges.

\section{2) Informatization construction has not followed up}

Information technology has played a catalytic role in promoting the reform and development of education, but the basic informationization of schools has not kept pace with the rapid development of schools. At present, most schools have not yet completed a school-level data center. None of the more than 70 higher vocational colleges in Hunan Province have realized a truly intelligent and intelligent campus. None of them has established a school-level data center, although the institutions They are aware of the importance of establishing a school-level data center, but one of the reasons for the lack of action may be that the various indicators of the education and government departments are constantly improving, and there is 
no fixed indicator system. The second reason is to establish a school. A data center is a big expense for every school.

\section{B. From the institutions of the Ministry of Education and Education and the directly affiliated institutions with administrative functions}

\section{1) Long-term leadership and long-term submission}

Since the national statistical management system is a centralized, unified, and hierarchical management system, there are different but overlapping roles between the Ministry of Education, the directly affiliated institutions, and the administrative departments. For the primary schools, they are all part of multiple education. The leadership of the government agencies, and the horizontal coordination between the education and government departments is not high, so there are multiple, repeated collections.

\section{2) Departmental government division.}

At the same time, due to the division of government affairs in the education and government departments, different departments have different division of labor and different responsibilities. They have different control points, control points, and timeliness. Therefore, when setting the index system of the report, it is mainly to meet the needs of the department. Connotation, the time of collection is different, but each department is in charge of the relevant situation of the school, so there must be repeated indicators, multiple, multiple collections exist. It is the division of government affairs that makes the direct information systems and data of the departments independent and cannot interact effectively and in time.

\section{3) Lack of data sharing mechanisms}

Although China has continuously reviewed the reform of the statistical system, it has not yet achieved real data sharing. There is a lack of mechanisms for data sharing and interconnection. The direct data of the Ministry of Education and the directly affiliated institutions are not shared, and there is a lack of data sharing between the education department and other government departments. In addition, the unclear responsibility of the data is also an obstacle to data sharing, because it has never been clear which data of the responsible entity will prevail.

\section{4) Data security is not guaranteed}

In addition, data security is one of the reasons that hinder data sharing. Information security and network security are the core issues under the conditions of informationization. The risk prevention of data sharing has always been a concern but there is no practical solution.

\section{At the national level}

\section{1) Institutional reasons}

The national system determines that China's statistical management system is centralized, unified, and responsible. This kind of management system determines that the various administrative agencies at all levels in China have a large and horizontal coordination system, the division of labor is not clear, and the responsibilities are intertwined. Although China is currently pushing forward the decentralization and decentralization, there is still a certain principle of streamlining and high efficiency. The gap, so the national system is one of the reasons for the data management problem.

2) At the national level, there is no unified design and promotion of the construction of big data centers in various industries

If the national level deploys and promotes the establishment of big data centers in various industries, the education system big data center will fall. So, the grassroots schools may not need to establish their own school-level data centers (or can directly extract data from the education system to the school). ), perhaps the birth of a school-level data center, to avoid the school out of touch with the times.

\section{THE COUNTERMEASURE ANALYSIS}

A. For the national level and the Ministry of Education and the institutions directly under the Ministry of Education

1) Develop and improve education data management systems and methods

The system is the key to ensuring the effectiveness of management regulations. The standardization of data resource management directly affects the quality of data. In order to strengthen the management of educational statistics in the Ministry of Education and directly under the institutions, to resolve the contradictions and problems affecting the quality of statistical data, to promote the standardized management, interconnection and sharing of various types of educational data, to better serve the reform and development of education, in accordance with " The Department of Development Planning and the Office of the Network Security and Informatization Leading Group of the Ministry of Education have formulated the Ministry of Education and its direct departments this year without repeating the collection, the source of one, the source, the provider, the responsibility, and the data security. Notice of the Administrative Measures for Educational Data of Institutions (Development and Development Department [2018] No. 1) to ensure the scientific standardized and institutionalized management of statistical data.

2) Focus on strengthening the construction of statistical information

In the era of rapid development of information technology, informationization has accelerated the multi-level growth of digital resources. It can be said that with the informatization, big data has become available, and data has become a recognized and important resource. The demand for data from all walks of life is increasing, data The importance of this is increasingly recognized. However, due to regional differences in the level of informatization construction in China, if data sharing is carried out on the top-level design and a unified data resource sharing exchange platform is established, the informationization level of each school must be kept up, so the National Informatization Leading Group We must work hard to balance the level of informatization construction in various places, strive for financial support, and strengthen regional technical exchanges. The National Medium- and Long-Term Education Reform and Development Plan (2010-2020) proposes to accelerate the construction of educational 
information infrastructure[4] and build a national education management information system.

\section{3) Establish a unified data center for educational data}

Due to the different functions of the educational and administrative departments, the jurisdiction is different, and the data sharing between the various government departments is not smooth. In the information age, all departments are informatized design and construction with the needs of the department. These information infrastructures exist. The characteristics of non-standardization, non-uniformity, and difficulty in reconciliation have actually caused waste of information construction. Therefore, the Ministry of Education can set up a unified educational data resource sharing platform. On the basis of uniform data fields, the business systems of the education and government departments can be connected to the shared platform, and the data exchange and sharing of different government departments can be realized [5].

\section{4) Open government affairs, data sharing}

Open government affairs and let power operate in the sun are not only the embodiment of the people's exercise of supervision, but also the party's long-term ruling philosophy. In the era of big data, the public demand for authoritative government information has increased dramatically. However, there is also a security risk of data disclosure in government affairs disclosure. Therefore, government affairs disclosure must have a sound legal system as a guarantee, establish data security, and share those data. The conditions for data sharing need to be legally guaranteed. Data sharing should be shared in a timely manner in accordance with the principle of "who is in charge, who provides, and who is responsible". At the same time, the departments and individuals who use the data are authorized and stipulated that they should bear the responsibility. The department of the data stipulates that it should be responsible. On this basis, we must promote the relevant mechanisms of data sharing.

\section{5) Further deepen institutional reform}

Because China's national system determines that China's various types of administrative agencies at all levels are large and horizontally coordinated, the division of labor is not clear enough, and there are overlapping responsibilities. The Party Central Committee attaches great importance to system reform. It has been exploring reforms in optimizing the allocation of functions, building a complete system, scientific and standardized, and efficient functional systems of the party and state institutions. The current decentralization, decentralization, and optimization of services are concrete manifestations. The Central Committee of the Communist Party of China's opinion on comprehensively deepening the reform of the education system pointed out that it is necessary to improve the macro management system of education, improve the service efficiency of the management department, and establish and standardize the information disclosure system.

\section{B. For primary schools}

1) Promote the implementation of the school-level data center

In the era of big data with data, that is, the possibility of mastering wealth, it is necessary for the management of the institutions to ideologically recognize the value of big data. Therefore, it is necessary to vigorously promote the actual case of the value of big data, and then the institutions are willing to act. The establishment of a school-level data center, of course, the state can also give some support. The establishment of school-level data centers is also important for improving the pace and quality of information construction.

\section{2) System, regulation first}

Effective institutional norms are the key to ensuring the orderly operation of school-level data centers, and are the cornerstone for ensuring that data plays its value. Establish and improve organizational structure, clarify the division of functions; systematically carry out the work of "preserving, abolishing, reforming, and establishing", starting from all links of education, teaching and personnel training, and establishing "conceiving, formulating, implementing, feedback, perfecting", etc. The normal mechanism of the system construction of the link forms a systematic system of data management that has standards beforehand, supervision in the event, and assessment after the event, and escorts the quality of personnel training in an all-round way.

Prepare the college's own data management system construction and operation plan; based on the professional quality objectives of cultivating high-quality technical and technical personnel, combing the personnel, finance, teaching, student affairs, teaching services, logistics support, research and development, industry-university cooperation, Information services, international exchanges and cooperation, supervision and control, etc., establish and improve the relevant data management system of the college, and form an internal control mechanism.

\section{3) Overall planning, unified standards}

Informatization construction requires the overall planning as the campus construction. It is based on the top command and decision system of the college. The top-level design is based on the national informationization development strategy outline, the "Code of Practice for Digital Campus Construction of Vocational Colleges", [2015] No.1, etc. The national-level teaching management information standard document, the Ministry of Education's "Education Management Information Standard (2002)", the part of higher education, combined with the school-level information management related documents, the overall planning of school information construction, in order to improve education and teaching information The level is the goal, the data of the teaching management business system is stored in the teaching-related table space, the data of the student management business system is stored in the student-related table space, and the data of the teacher management business system is stored in the teacher-related data table. In the space, the training, post-internship, scientific research, finance, fixed assets and other data are classified and stored, and the school-based data platform with the data volume not lower than the national "status data" platform is 
established to serve the reform and development of school education and teaching.

\section{4) Create conditional use data}

Vigorously publicize the value of data and the frequency of use of data, use data in scientific research workloads, teaching rewards, and other personal and team performance assessments, so that teachers and students can see the charm and attractiveness of data; create conditions to use data, repeat Exploit the benefits of each business system and let management realize that effective management is based on quantitative and objective data. When the frequency of using data increases and the defects of not using data are highlighted, it will force schools to think about how to standardize school data management. How to break the functional division of information systems, information systems and data are independent and ineffective. The problem of interactive sharing solves the problem of how to achieve a better interface between the management layer and the service layer, and then promotes the completion of the school-level data (shared platform).

\section{CONCLUSION}

Based on the problems in the education statistics in the context of information disclosure, the reasons for the problems are analyzed from the level of the school, the Ministry of Education, the directly affiliated institutions with administrative functions, and the state: from the school level, each digital business system Software independence, informatization construction has not been followed up; from the Ministry of Education and Education and the directly affiliated institutions with administrative functions, long-term leadership, multi-head reporting, departmental government division, lack of data sharing mechanism, data security is not guaranteed; from the state At the level, institutional reasons, the national level has not unified design and promote the completion of big data centers in various industries.

A targeted countermeasure is proposed for the cause of the problem. For the national level and the Ministry of Education and directly affiliated institutions, it is necessary to formulate and improve the education data management system and methods, and strive to strengthen the construction of statistical information, establish a unified data center for educational data open government affairs, data sharing, and further deepen. System reform; for grassroots schools, promote the implementation of school-level data centers2Implementation, system, norm first, overall planning, unified standards, create conditions to use data.

\section{REFERENCES}

[1] Xuzhi Gao. Thinking and exploration of the construction of state-owned assets management information in colleges and universities [j], administrative assets and finance, 2019 (01)

[2] Jing Cheng. Problems and Countermeasures of Effective Utilization of Educational Statistics in the Background of Big Data_ Based on the Thinking of Basic Statistics in Higher Education[J]. Value Engineering, 2017-12-28

[3] Yiwen Cui. Research on the value of "smart campus" construction in the era of smart phones [j]. E-commerce, 2015(04)

[4] Respondent of the Office of the Working Group of the National Medium- and Long-Term Education Reform and Development Education Plan (2010 2020) [j]. Evaluation and Management, 2010(9): $22-25$

[5] Xiaodong Wang et al. Regional education management public service platform and basic database construction practice - based on provincial education data center [j]. China Education Informationization, 2016(7)

[6] Wanli Gao, Yuan Xianzhen. Exploration of the statistical work of higher vocational education under the background of cloud computing [j], 2016(01): 52-53 